\title{
Toward a more professional and practical medical education: a novel Central European approach
}

This article was published in the following Dove Press journal:

Advances in Medical Education and Practice

23 June 2015

Number of times this article has been viewed

\author{
Heinz Drexel ${ }^{1-4, *}$ \\ Alexander Vonbank ${ }^{1-3, *}$ \\ Peter Fraunberger ${ }^{3,5}$ \\ Walter F Riesen ${ }^{3}$ \\ Christoph H Saely ${ }^{1-3}$ \\ 'Vorarlberg Institute for Vascular \\ Investigation and Treatment, \\ ${ }^{2}$ Department of Medicine and \\ Cardiology, Academic Teaching \\ Hospital Feldkirch, Feldkirch, \\ Austria; ${ }^{3}$ Private University of the \\ Principality of Liechtenstein, Triesen, \\ Liechtenstein; ${ }^{4}$ Drexel University \\ College of Medicine, Philadelphia, PA, \\ USA; ${ }^{5}$ Medical Central Laboratories, \\ Feldkirch, Austria \\ *These authors contributed equally \\ to this work
}

\begin{abstract}
We here present an innovative curriculum for a complete medical education that conforms to the current European Bologna system of academic training. The curriculum aims at raising doctors who are excellently prepared for clinical work over as short a time as 5 years; it provides a comprehensive, yet shorter than usual, education that strongly pronounces the importance of increasing the students' practical clinical competences and rigorously excludes superfluous contents. The curriculum encompasses 52 modules, 32 at the bachelor's and 20 at the master's level. Already at the level of the bachelor degree, full employability is given; the students finish the master's course as medical doctors optimally prepared to manage patients at the level of postgraduate medical education. The structure of the curriculum is modular; each modular component is essential for medical education and contains an average of five European Credit Transfer System credits, amounting to 150 hours of education. Depending on the subspecialty, the courses include lectures, seminars, practical laboratory training, and clinical training at varying quantities. In addition to attendance times, sufficient time slots are prepared for self-study in lectures, seminars, and practical work. With our curriculum, we provide an easily applicable backbone for a modern course of medicine that can be installed also at smaller academic institutions.
\end{abstract}

Keywords: Bologna criteria, medical education, bedside teaching, practical medical education

\section{Introduction}

\section{Inside and around the university}

Medical education faces numerous challenges. Curriculum development at a medical university is critically dependent on established clinical, laboratory, and staff prerequisites. Environmental ramifications such as the availability of a campus and rooms may cause additional problems. ${ }^{1,2}$ Limited resources and political interests further impair an optimal curriculum development.

There are reformed and integrated curricula that use organ-based teaching together with early clinical skills teaching and problem-based learning not only in the US but also at European universities. However, many existing European curricula while following an organ- or system-based approach with regard to didactics, strongly reflect what has been traditionally taught at medical universities with regard to contents. Furthermore, most existing curricula do not meet the Bologna criteria for both Bachelor's and Master's degrees. ${ }^{3,4}$ Our curriculum aims at adopting organ- or disease-based teaching together with early clinical skills teaching and problem-based learning, both at the Bachelor's and
Correspondence: Heinz Drexel Department of Medicine and Cardiology, Academic Teaching Hospital Feldkirch, Carinagasse 47, A-6807 Feldkirch, Austria Tel +4355223032670

Fax +435522 3037533

Email vivit@lkhf.at request permission may be found at http:///www.dovepress.com/permissions.php 
Master's degree levels, with a stronger focus on practical clinical relevance than in any other curriculum we are aware of.

\section{A private institution}

The Private University of the Principality of Liechtenstein ${ }^{5}$ is a purely private institution with no political dependence, and sponsoring is entirely private. Therefore, no commitments need to be made with governmental interests. On this basis of our university, we decided to develop a Bachelor's and Master's curriculum for human medicine, deemed as optimal as possible. It meets the Bologna criteria ${ }^{3}$ and provides an optimal basis for the students to become well-trained physicians. The curriculum committee is well experienced in the development of degree courses. Most importantly, a doctoral degree of scientific medicine as well as a dual Doctorate of Medicine and of Philosophy (an MD-PhD) course has successfully been implemented at the same university. The whole curriculum has been developed and refined by a multidisciplinary committee over a period of more than 3 years. Moreover, other curricula have been developed with participation of one of us (HD), including the current curriculum of the Medical University of Innsbruck, as well as a postgraduate course in clinical geriatrics.

A number of nearby hospitals alone or together meet the criteria for a clinical campus, including teaching staff, clinical facilities, wards, outpatient clinics, and teaching rooms.

\section{Well-educated doctors in a short time}

The aim of every curriculum is to raise excellent physicians. On the basis of a sound scientific background and today's practice, optimal preparation of students for the profession of a physician is feasible in less than usual time ${ }^{6}$ here, we plan a 5-year curriculum.

\section{Comprehensiveness}

A brief general introduction to the biomedical sciences is fundamental. However, to allow for short duration, the curriculum teaches organ-specific disease by comprehensive modules combining basic and clinical knowledge. Main features of such a curriculum include bedside teaching from the very beginning, with close relation to science and evidence.

\section{Didactic concept}

Didactic methods encompass classical lectures with newest teaching methods, intensive clinical training, and e-learning; ie, blended learning should enable students to gain both theoretical and practical medical knowledge within a short time. Furthermore, careful selection and permanent training of teachers ("train-the-trainer seminars") are to occur. Finally, feedback mechanisms for both teachers and students should guarantee high standards during the whole course. Because personal interaction between students and educators is of utmost importance, the number of students per class is strictly limited to a maximum of 30 , with lower numbers for practical units.

We here present our innovative medical curriculum, which meets all the criteria postulated above.

\section{Core contents Bologna system}

Consistent with the Bologna system ${ }^{3}$ of academic training, a six-term bachelor's course is the basis of the curriculum, followed by a four-term master's course, ie, a total of 5 years of studies. Each of these courses is completed with an academic degree (Bachelor of Medicine and Master of Medicine, respectively). The overall structure of the curriculum is summarized in Table 1.

\section{Bachelor's degree}

The bachelor course starts with a general introduction covering general physiology, biochemistry, anatomy, histology, embryology, clinical chemistry, human genetics, immunology, microbiology, pharmacology, toxicology, and general health care, which enables students to understand the ensuing curricular contents. Importantly, patient-oriented and thus problem-based learning is a central feature of training already in this very first step of education at our university. Thereafter, structure, function, and major mechanisms of dysfunction of organ systems are covered. This block dealing with organ systems equips students with the basic knowledge of human health and disease.

\section{Twelve essential diseases}

One essentially novel approach of our curriculum is the next large block focusing on the "twelve most important diseases", covering an array of important conditions from back pain to diabetes mellitus. This focus on a set of the most important diseases appears helpful both from a clinical and from an educational viewpoint. By this approach, two major effects are intended: First, more than $80 \%$ of daily clinical work of residents and general practitioners deals with these most important diseases; in-depth knowledge of their management at an early stage of medical education enables students to undergo efficient practical work and thus provides an optimal basis for bedside teaching throughout 


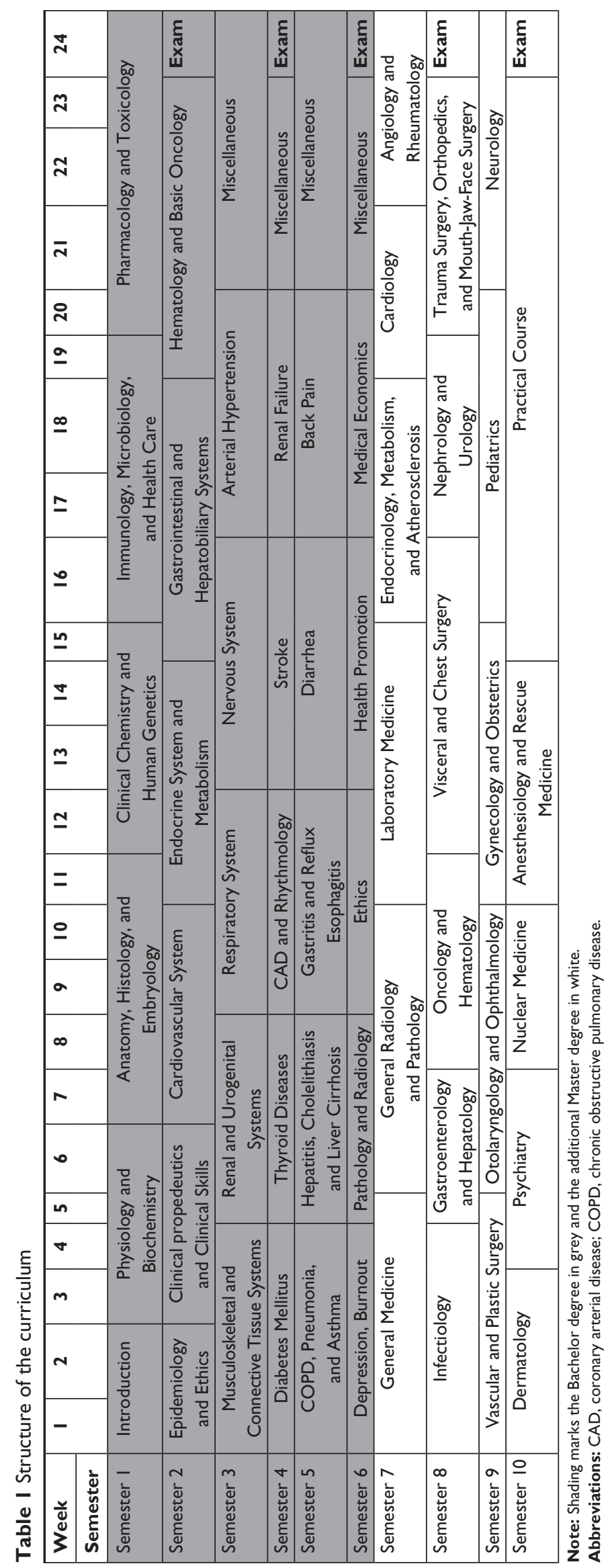


the curriculum. ${ }^{7}$ Second, the art of clinical decision making requires in-depth knowledge. Having gained detailed experience in these most important diseases, students will be able to better understand not only their management but also general medical decision making. Consequently, these two facets of early professionalism strengthen student motivation.

\section{Enlarging bachelor contents}

The bachelor curriculum is completed with modern general medical topics such as health promotion, ethics, and medical economics, which provide a broad general medical education already at this level. Most importantly, patient-oriented learning, as a special type of problem-based learning, guarantees clinical experience already at the bachelor level for these graduates. Other types of problem-based learning used in our curriculum are paper cases or focused reviews of the literature. This enables them to transcend into the distinctively clinically oriented master's course.

\section{Master's degree}

The paramount goal of the master's course is to raise doctors who are able to decide on therapy of patients. To meet this expectation, the master's course starts with a broad, almost totally clinically orientated block of general medicine, wherein students spend large amounts of time at emergency clinics or private general medicine practices. This is followed by courses covering the standard clinical subspecialties such as visceral and chest surgery, internal medicine, pediatrics, gynecology, or neurology. In addition, general concepts as well as clinically important in-depth knowledge of important cross-disciplinary specialties, eg, clinical pathology or radiology are acquired. At the end of the master course, a large block of exclusively clinical work follows at the hospital wards, covering different subspecialties.

\section{Scientific training}

Insights into scientific methods and principles are of major importance for the understanding and interpretation of results from trials that lead to changes in the treatment of patients. Therefore, even though it is not the primary intention of our curriculum to educate scientists, students receive scientific training as part of their preparation courses for their Bachelor and Master theses, including basics of scientific reading and writing, project planning, and biostatistics. These curricular contents are taught at the Private University of Liechtenstein, where we have already implemented a very successful postgraduate doctoral program, with 10 years of experience. Details concerning this program can be seen at the homepage of the Private University of the Principality of Liechtenstein. ${ }^{5}$

\section{United States Medical Licensing \\ Examination conformity}

Finally, to secure a high international standard of quality, all students must have completed United States Medical Licensing Examination Step 1 as well as Step 2 Clinical Knowledge before graduating as Masters of Medicine. ${ }^{8}$ Online-based courses are available for training and preparation.

\section{Contents to be avoided Lengthiness}

A good medical curriculum provides a framework that helps students to be optimally prepared for postgraduate medical education in as short a time as necessary to fully obtain all required knowledge and skills.

\section{Superfluous contents}

Inclusion of curricular content that is not helpful to improve the understanding of concepts or the management of patients is uneconomical both in terms of time and of economical resources and therefore must be avoided. This in particular holds true for unnecessary factual knowledge that neither significantly promotes conceptual understanding nor improves patient management. For example, learning to morphologically differentiate right- from left-handed ossa carpalia may be a pleasing diversion for some and has been taught in established European medical schools until recently; however, it will hardly affect patient management skills or scientific productivity of medical students.

\section{Contents of mere historical value}

Typically, representatives of medical subspecialties teach their fields of expertise. In this context, it is important to consider that the subdivision of medicine into its various disciplines has grown historically but is inherently arbitrary: there is an enormous overlap between many medical subspecialties. To guarantee optimal medical education in the shortest possible time, overlap between medical subspecialties that entails overlap in curricular contents must be avoided. Indeed, patientoriented learning should be given priority over subspecialtydriven learning in modern medical education. For example, the biochemical cascade of blood clotting is taught as much as five times during a typical conventional European medical education, whereas clinical management of anticoagulation therapy is hardly considered. 


\section{Outdated contents}

Finally, medicine is a continually evolving science. What has constituted curricular content in the past, today, frequently is outdated or of minor importance for the students' understanding or future patient management. Educational content that has been kept in curricula only or primarily for historical reasons must be abandoned to secure time and the economical resources needed to communicate the knowledge and skills a medical doctor needs today. Discussing the basic pharmacology of a class of drugs that is no longer in clinical use (such as reserpine in the treatment of arterial hypertension) or obsolete procedures (such as superselective vagectomy for peptic ulcers) does not appear appropriate in the context of evidence-based medicine. Today, a curriculum neglecting the omnipresence of evidence-based medicine would be deemed inadequate.

\section{Results: description of the curriculum Modular concept}

The curriculum encompasses 52 modules, 32 at the bachelor's and 20 at the master's level. Each modular component is essential for medical education and contains an average of five European Credit Transfer System credits, amounting to 150 hours of education. Depending on the subspecialty, the courses include lectures, seminars, practical laboratory training, and clinical training at varying quantities. In addition to attendance times, sufficient time slots are prepared for self-study in lectures, seminars, and practical work.

\section{Examples}

Tables 2 and 3 show detailed descriptions of Bachelor's course 2 (Physiology and Pathobiochemistry) and Master's course 5 (Cardiology) as examples. In accordance with our main intention to optimally prepare doctors for clinical work, a large amount of time is spent on practical clinical training, eg, history taking and physical examination, electrocardiogram and echocardiography interpretation. This practical clinical training is rounded off by lectures and seminars, which focus on providing students with the background knowledge necessary for clinical work. Students get an introduction in general cardiology in 20 hours of classical lectures, complemented with 10 hours of self-study. Important special considerations are interactively discussed in a seminar ( 10 hours +5 hours of self-study). Basic cardiologic skills such as electrocardiogram interpretation or physical examination are systematically taught in a clinical practice unit of 15 hours. A large block of 60 hours is spent on the cardiology ward, where students learn at the bedside.

\section{Specific didactical aspects}

A homogeneous didactical concept underlies both the Bachelor and Master curricula. Most importantly, there is a focus on learning-by-doing and thus intense clinical practice from the very beginning. Some important specific aspects are outlined below:

1. Because personal interaction between teachers and students is essential, the number of students per course is strictly limited. In particular, in practical clinical work, the student per teacher ratio must not exceed 5.0.

2. Interactive educational tools including blended learning, paper cases, and doughnut rounds are broadly used. ${ }^{9}$

3. To optimally prepare students for medical practice, which is essentially patient oriented, problem-based learning is implemented throughout the curriculum. As has been shown previously, problem-based learning also improves interpersonal skills and psychosocial knowledge, as well as the overall attitude toward patients. ${ }^{10}$ Clinical skills are taught at bedside but also in skills laboratories and simulation environments (eg, resuscitation dolls or interpretation of radiologic images).

4. Assessments not only are important to monitor successful acquisition of knowledge but also serve as a major didactical tool to direct the students' attention to the most important aspects as well as to recapitulate and memorize key facts and major skills. They are planned at three levels: i) at course level, ii) at modular level, and iii) at program level. Course-level assessments are achieved from the students' continuous presence at and contributions to the courses rather than by formal examinations. Modular examinations aim at assessing the student's detailed knowledge and skills acquired in the respective modules. Furthermore, there are Objective Structured Clinical Examination ${ }^{11}$ assessments in this part, in which candidates are examined on a one-to-one basis with one examiner and either real or simulated patients. Candidates rotate through various stations. Modules are successfully completed only when the respective modular examinations have been completed successfully. Examinations at the program level take place once a year and assess the students' familiarity with key concepts from the single modules as well as their ability to link contents learned in single modules. Examinations at the modular or program level can be retaken a maximum of three times. 
Table 2 Detailed structure and description of bachelor module 2, Physiology, Biochemistry, and Pathobiochemistry

\begin{tabular}{|c|c|c|c|c|c|c|}
\hline $\begin{array}{l}\text { Module 2: Physiology, Biochemistry, } \\
\text { and Pathobiochemistry }\end{array}$ & Type & $\begin{array}{l}\text { Number of } \\
\text { students }\end{array}$ & $\begin{array}{l}\text { Attendance } \\
\text { time (hours) }\end{array}$ & $\begin{array}{l}\text { Self-study } \\
\text { (hours) }\end{array}$ & $\begin{array}{l}\text { ECTS } \\
\text { credits }\end{array}$ & Facility \\
\hline Sum of the hours and credits & & & 100.0 & 55.0 & 5.0 & \\
\hline Basics in Physiology and & Lecture and & 30.0 & 40.0 & 20.0 & 2.0 & Lecture Hall \\
\hline Biochemistry & Practical Training & & & & & Laboratory \\
\hline Introduction into Pathobiochemistry & Seminar & 30.0 & 40.0 & 20.0 & 2.0 & Multifunctiona \\
\hline and Pathophysiology & & & & & & Room \\
\hline Paper Cases and Clinical Physiology & Clinical Practice & 15.0 & 20.0 & 10.0 & 1.0 & Clinic \\
\hline
\end{tabular}

\section{Module number: 2}

Position within the curriculum Skills Acquisition

Course Title

Credits

Position within the curriculum

Teaching methods

Conditions and mode of examination

Topics/course content

Position within the curriculum

Skills Acquisition

Course Title

Credits

Position within the curriculum

Teaching methods

Conditions and mode of examination

Topics/course content

Position within the curriculum

Skills Acquisition

Course Title

Credits

Position within the curriculum

Teaching methods

Conditions and mode of examination

Topics/course content
Name of module: Physiology, Biochemistry, and Pathobiochemistry

First Semester of Bachelor Course

See topics/course content and notes

Basics in Physiology and Biochemistry

2 ECTS

First Semester

Lecture

Written Examination

Physiological methods, elements of the nervous system and their function, basic neurophysiology

(depolarization and repolarization), sensory system, motor system, integrative function of the nervous system, blood and oxygen transport, cardiovascular system, respiration, adaptation of the organism to altitude, kidneys, acid-base metabolism, gastrointestinal tract, energy balance and nutrition, thermal balance and temperature regulation, skin, reproduction, coordination of specific organ functions, performance, and aging and death. Carbohydrates, lipids, amino acids, peptides and proteins, intermediate metabolism, enzymes, vitamins and trace elements, hormones, diet, digestion and resorption, blood, cell biology, and molecular biology.

First Semester of Bachelor's Course

See topics/course content and notes

Introduction into Pathobiochemistry and Pathophysiology

2 ECTS

First Semester

Seminar

Written Examination

Exemplary malfunctions of nervous system, sensory system, motor system, integrative functions of the nervous system, blood and oxygen transport, cardiovascular system, respiration, adaptation of the organism to altitude, kidneys, acid-base metabolism, gastrointestinal tract, energy balance and nutrition, thermal balance and temperature regulation, skin, reproduction, and coordination of specific organ functions.

Carbohydrate metabolism, lipid metabolism, amino acid metabolism, peptides and proteins, intermediate metabolism, enzymes, vitamins and trace elements, hormones, diet, digestion and resorption, blood, cell biology, and molecular biology.

First Semester of Bachelor's Course

See topics/course content and notes

Paper Cases and Clinical Physiology

I ECTS

First Semester

Clinical Training

Written Examination

Hyperventilation, diving and flying, digestion (fasting and postprandial), practical exercises and paper cases to nervous system, sensory system, motor system, integrative functions of the nervous system, blood and oxygen transport, cardiovascular system, respiration, adaptation of the organism to altitude, kidneys, acid-base metabolism.

Gastrointestinal tract, energy balance and nutrition, thermal balance and temperature regulation, skin, reproduction, and coordination of specific organ functions.

Carbohydrate metabolism, lipid metabolism, amino acid metabolism, peptides and proteins, intermediary metabolism, enzymes, vitamins and trace elements, hormones, diet, digestion and resorption, blood, cell biology, and molecular biology.

Notes: Professor/instructor prerequisites: PhD, train-the-trainer education. Skills Acquisition: The students are able to use their knowledge in broad scientific principles and disciplinary topics in physiology, biochemistry, and pathobiochemistry to derive important physiological, biochemical, and pathobiochemical mechanisms for practical use in human medicine. They apply their knowledge for a comprehensive understanding of etiology, pathogenesis, clinics, and therapy of human diseases. On the basis of their knowledge in physiology, biochemistry, and pathobiochemistry, they can give a critical opinion on specific diagnostic and therapeutic measures.

Abbreviation: ECTS, European Credit Transfer System. 
Table 3 Detailed structure and description of master module 5, cardiology

\begin{tabular}{|c|c|c|c|c|c|c|}
\hline Module 5: Cardiology & Type & $\begin{array}{l}\text { Number of } \\
\text { students }\end{array}$ & $\begin{array}{l}\text { Attendance } \\
\text { time (hours) }\end{array}$ & $\begin{array}{l}\text { Self-study } \\
\text { (hours) }\end{array}$ & $\begin{array}{l}\text { ECTS } \\
\text { credits }\end{array}$ & Facility \\
\hline Sum of the hours and credits & & & 105.0 & 15.0 & 4.0 & \\
\hline Cardiology & Lecture & 30.0 & 20.0 & 10.0 & 1.0 & Lecture Hall \\
\hline Special Issues in Cardiology & Seminar & 30.0 & 10.0 & 5.0 & 0.5 & Lecture Hall \\
\hline $\begin{array}{l}\text { Physical Examination Skills } \\
\text { in Cardiology }\end{array}$ & Practical Training* & 5.0 & 15.0 & 0.0 & 0.5 & $\begin{array}{l}\text { Lecture Hall } \\
\text { and Clinic }\end{array}$ \\
\hline Cardiology in Practice & Clinical Practice** & 5.0 & 60.0 & 0.0 & 2.0 & Clinic \\
\hline
\end{tabular}

\section{Module number: 5}

Position within the curriculum

Requirements

Skills Acquisition

Course Title

Credits

Position within the curriculum

Teaching methods

Conditions and mode of examination

Topics/course content

Position within the curriculum

Requirements

Skills Acquisition

Course Title

Credits

Position within the curriculum

Teaching methods

Conditions and mode of examination

Topics/course content

Position within the curriculum

Requirements

Skills Acquisition
Course Title
Credits
Position within the curriculum
Teaching methods
Conditions and mode of examination
Topics/course content

Position within the curriculum

Requirements

Skills Acquisition

Course Title

Credits

Position within the curriculum

Teaching methods

Conditions and mode of examination

Topics/course content
Name of module: Cardiology

\section{Credits: 4 ECTS}

First Semester of Master Course

Bachelor's Degree

See topics/course content

Cardiology

I ECTS

First Semester

Lecture

Oral Examination

Clinical history, diagnostics and management of coronary artery disease, inflammatory heart diseases, valvular heart diseases, heart failure, congenital and acquired heart diseases, rhythm disorders (especially atrial fibrillation), sudden cardiac death, synkopes, and pericardial diseases First Semester of Master Course

Bachelor's Degree

See topics/course content

Special Issues in Cardiology

0.5 ECTS

First Semester

Seminar

Oral Examination

Case report analysis of selected lecture topics

First Semester of Master Course

Bachelor's Degree

See Description of Module 5

Physical Examination Skills in Cardiology

0.5 ECTS

First Semester

Practical Training

Oral Examination

ECG: placement of ECG electrodes and mutual assessment of ECG results (under guidance); echocardiography: demonstrations and analysis of sectional planes, ergometric exercise, coronary angiography filming, and heart and chest radiography

First Semester of Master Course

Bachelor's Degree

See topics/course content

Cardiology in Practice

2 ECTS

First Semester

Clinical Training

Oral Examination

Practical application of acquired knowledge and skills in clinical divisions and outpatient departments, guided management of particular medical cases (especially assessment of the student's own ECG results), echocardiography: demonstrations of sectional planes on real patients, ergometric exercise, coronary angiography filming, and the heart in chest radiography.

Notes: *Instruction in physical examination (eg, ultrasonography in a group of students); **working with patients (eg, diagnostics, interpretation of diagnostic findings). Professor/ instructor prerequisites: PhD, train-the-trainer education. The students are able to use their knowledge of definitions, epidemiology, etiology, pathophysiology, clinical history, complications, therapy, and prognosis of cardiac diseases for an efficient global management of cardiac patients while balancing different modern therapy options for optimal treatment. They have acquired the necessary skills to apply their knowledge effectively, safely, and cost-efficiently in the health care of cardiac patients.

Abbreviations: ECG, electrocardiogram; ECTS, European Credit Transfer System. 
5. To enforce a homogeneous didactical concept among all modules throughout the curriculum, train-the-trainer seminars are obligatory for anyone teaching at our university; regular didactical updates are essential for maintaining a tenured position at our university. We strictly demand a uniform didactical approach throughout the curriculum. To this end, train-the-trainer courses must be completed before being admitted to our faculty and then at least biannually to maintain faculty status. These courses cover the general structure of teaching modules, instructions on how to create illustrative slides, rhetorical skills, assessment to promote learning, and assessment of learning progress and status and thus are similar to common Medical Education Programs. Only guest lecturers are exempt from this general rule.

\section{Quality management}

There are different evaluation levels for the quality management of our curriculum. Continuous feedback not only is given by teachers to students but students also provide feedback through evaluation of the courses.

The first level is student evaluation with a standardized questionnaire of the single course. The second level is the annual student evaluation of the main courses to collect organization, contentment, amount of work, etc.

Continuous development of the curriculum is based on different points: administration statistics, feedback by teachers and students, and a periodic evaluation of the curriculum by external experts.

\section{Potential pitfalls}

A potential pitfall might include financing of the program. Our curricular working group has addressed this issue. Of course, cost/benefit calculations will vary due to local differences in costs and willingness to pay for medical education. For the region of Central Europe where the curriculum has been drafted, we find that with an annual fee of $30,000 €$ per student, the program is self-sustained.

Another theoretical pitfall is lack of demand. The huge numbers of young men and women applying for medical school at least in Central Europe together with the limited number of study places available render lack of demand a very unlikely obstacle to successful implementation of the program.

\section{Discussion}

We herein present a Bachelor-Master curriculum that is innovative in many ways.
First, the concept is free of external constraints, ie, no historical obligations - like an employment of an ancient structure - were to be met.

Second, the curriculum is comprehensive in that clinical orientation is melted with basic knowledge from the very beginning on. In particular, the focus on clinical practical issues results in well-trained physicians, who are prepared to immediately care for patients. In the development phase of our curriculum, we extensively studied existing curricula of several existing institutions. Our curriculum aims at adopting organ- or disease-based teaching together with early clinical skills teaching and problem-based learning, with a stronger focus on practical clinical relevance than in any other curriculum we are aware of.

Third, the courses are unusually efficient because they avoid outdated contents and unnecessary replication. In addition, the teaching methods are chosen to provide fast progress in knowledge.

Fourth, we use a concept of classes with a maximum of 30 students. This fosters the short duration of 5 years only for the whole curriculum. This in turn allows for a slim teaching crew. In particular, we calculated a need for only 18 full-time teachers at the resident level. Together, these four points offer essential advantages over many existing curricular approaches.

The usefulness of a separate Bachelor course in a curriculum of medicine has been debated widely, mainly because the professional outlook was not clear. However, with our practicality approach, bachelor graduates can be employed in a number of professional positions. Examples are outdoor positions in the pharmaceutical industry, as administrative assistants in hospital documentation, as officers in public health, and as laboratory and radiology technicians (with additional specific training).

The Bachelor conception enables the graduates' entry not only into the medical master's course, but also into other master's courses, eg, sports sciences or Master of Business Administration.

Altogether, with our curriculum, we have developed an easily applicable backbone for a modern course of medicine. We intend to install the present curriculum soon at our university and teaching hospital or elsewhere. We publish it because we want to elicit further discussion. We are aware of the fact that a curriculum is never final or perfect.

\section{Acknowledgments}

The curriculum group of Vorarlberg consisted of Karl Fenkart, Erwin Bahl, Karl Keckeis, and Heidrun Schöch. 
The curriculum group of Liechtenstein was composed of Willi Ribi, Karl Sudi, and Barbara Gant.

\section{Disclosure}

The authors report no conflicts of interest in this work.

\section{References}

1. Balmer JT. The transformation of continuing medical education (CME) in the United States. Adv Med Educ Pract. 2013;4:171-182.

2. Bhutta ZA, Chen L, Cohen J, et al. Education of health professionals for the 21st century: a global independent commission. Lancet. 2010; 375(9721):1137-1138.

3. Bologna Declaration. 2014. Available from: http://europa.eu/ legislation_summaries/education_training_youth/lifelong_learning/ c11088_en.htm. Accessed February 10, 2014.

4. Patricio M, de BC, Costa MJ, Schirlo C, ten Cate O. Bologna in Medicine Anno 2012: experiences of European medical schools that implemented a Bologna two-cycle curriculum - an AMEE-MEDINE2 survey. Med Teach. 2012;34(10):821-832.
5. Private University of the Principality of Liechtenstein (UFL). 2015. Available from: http://www.ufl.li. Accessed February 21, 2015.

6. Michaud PA. Reforms of the pre-graduate curriculum for medical students: the Bologna process and beyond. Swiss Med Wkly. 2012; 142:w13738.

7. Dewji R, Dewji A, Gnanappiragasam D. Back to basics: tackling the challenges to bedside teaching. Adv Med Educ Pract. 2015;6:17-18.

8. Berner ES, Brooks CM, Erdmann JB. Use of the USMLE to select residents. Acad Med. 1993;68(10):753-759.

9. Bridges SM, Dyson JE, Corbet EF. Blended learning, knowledge coconstruction and undergraduate group work. Med Educ. 2009;43(5): 490-491.

10. Jones NL, Peiffer AM, Lambros A, et al. Developing a problem-based learning (PBL) curriculum for professionalism and scientific integrity training for biomedical graduate students. J Med Ethics. 2010;36(10): 614-619.

11. Abdelaziz A, Hany M, Atwa H, Talaat W, Hosny S. Development, implementation, and evaluation of an integrated multidisciplinary objective structured clinical examination (OSCE) in primary health care settings within limited resources. Med Teach. Epub 2015:1-8.

\section{Publish your work in this journal}

Advances in Medical Education and Practice is an international, peerreviewed, open access journal that aims to present and publish research on Medical Education covering medical, dental, nursing and allied health care professional education. The journal covers undergraduate education, postgraduate training and continuing medical education including emerging trends and innovative models linking education, research, and health care services. The manuscript management system is completely online and includes a very quick and fair peer-review system. Visit http://www.dovepress.com/testimonials.php to read real quotes from published authors.

Submit your manuscript here: http://www.dovepress.com/advances-in-medical-education-and-practice-journal 